\title{
Incident Angle and Light Intensity Variation: a Comparative Impact Study on Perovskite, Dye-sensitized and Silicon Heterojunction Solar Cells Towards Building-Integrated Applications
}

\author{
V. Stockhausen ${ }^{\mathrm{a}}$, L. Andrade ${ }^{\mathrm{a}}$, D. Ivanou ${ }^{\mathrm{a}}$, B. Stannowski ${ }^{\mathrm{b}}, \mathrm{A}$. Mendes $^{\mathrm{a}, *}$ \\ ${ }^{\text {a } L E P A B E}$, Departamento de Engenharia Química, Universidade do Porto - Faculdade de Engenharia, Rua Dr. Roberto Frias s/n, $4200-465$ Porto, Portugal \\ ${ }^{\mathrm{b}}$ Helmholtz-Zentrum Berlin für Materialien und Energie, PVcomB, Berlin, Germany
}

A R T I C L E IN F O

\section{Keywords:}

Perovskite solar cells (PSC)

Silicon heterojunction (SHJ) solar cells

Dye-sensitized solar cells (DSC)

Building-integrated

Incident angle

Light intensity

\begin{abstract}
A B S T R A C T
To make the concept of building-integrated solar cells viable, the latter should possess an increased tolerance towards light incident angle and intensity that naturally change along the day, among other required properties. In this work, three solar cell technologies as candidates for building-integrated applications are compared regarding their normalized average efficiency as a function of light intensity and incident angle. The mechanisms that lead to higher efficiency independence are evidenced by comparing several cell designs for dye-sensitized solar cells (DSC) and perovskite solar cells (PSC). By doing so, it was found that superior efficiency independence towards tilted light is obtained for PSC with more transparent active layers due to optical path lengthening (OPL), while DSC were found to exhibit OPL in standard configuration. All cells show a fairly stable efficiency evolution when light intensity was reduced, while at lower light intensity PSC slightly outperform DSC. The almost constant relative efficiency evolution of silicon heterojunction (SHJ) solar cells is a very interesting outcome of this work and so far, efficiency evolution of such SHJ under low light intensity have not been reported in the literature to the best of our knowledge.
\end{abstract}

\section{Introduction}

It has been widely recognized that worldwide anthropogenic activities have led to a permanent increase of $\mathrm{CO}_{2}$ levels above $400 \mathrm{ppm}$ in 2016, a benchmark value for climate change, and that there are no indications for any regression for the next decades [1]. Thus, more than ever, there is an urgent need to replace carbon-emitting energy technologies by renewable energy sources on a massive scale. In Europe, both wind and solar energy plant installation continued to increase substantially after the Paris Agreement in 2015. In 2014, their combined net production in Europe already reached 340 TWh but to achieve the binding target of 1000 TWh till 2030, the implementation of both technologies has to triple [2]. While wind power plants can be only mounted in remote areas due to their considerable visual and noise impact on the surrounding, solar power installations are very versatile and moreover, can be introduced into habitations and cities as buildingintegrated photovoltaic (BIPV) solutions. This means that solar modules make part of the building envelope, which opens a whole new architectural field of creativity as solar cells, according to the technology, can be opaque or semitransparent. This fusion is undoubtedly more challenging from a technical point of view, but will turn indispensable as soon as photovoltaic production will effectively become ubiquitous in densely populated areas $[3,4]$.

For achieving BIPV solutions that present a satisfying cost-benefit ratio, solar cells must fulfill several criteria such as stability towards temperature, moisture and atmospheric oxygen, low manufacturing cost, aesthetics (color tunability, transparency) as well as maximum independence of light intensity and incident angle. Within the photovoltaics market, silicon-based modules have been dominating so far, with crystalline silicon $(c-\mathrm{Si})$ cells being the predominant technology. Silicon heterojunction (SHJ) solar cells, as a more recent technology, hold great promise to overcome inherent limitations of $c$-Si, such as low $V_{\mathrm{OC}}$ and charge carrier recombination, while maintaining its advantages such as abundance of the precursor materials, high stability and low toxicity [5] at comparable fabrication costs [6]. Dye-sensitized solar cells (DSC) are at the verge of commercialization, representing a technology that could work out particularly well in warmer climate zones $[7,8]$. Due to their semitransparency and possibility of colortuning, they have been already studied for building-integrated concepts [9-11]. Furthermore, DSC are reported to exhibit higher efficiencies at

\footnotetext{
* Corresponding author.

E-mail address: mendes@fe.up.pt (A. Mendes).
} 
lower light intensities [12] and under indoor illumination [13,14]. Perovskite solar cells (PSC) are still at the stage of investigation, but have attracted a lot of attention due to their stunning performance evolution since 2012 [15]. Since then, PSC efficiencies have been reaching certified record efficiencies of $22.7 \%$ for laboratory devices [16]. As PSC do not exhibit sufficient stability towards temperature [17] and humidity [18,19] yet, encapsulation technology is a must $[20,21]$. Lately, very promising results in laser-assisted glass frit sealing for PSC applications were achieved in our research group [22]; however, this topic is still matter of ongoing research. Thus, the present study does not include outdoor stability tests and focuses on the influence of incident angle and incident light intensity on the efficiency of these three solar cell technologies. In fact, efficiency losses due to incident angle dependency may even be the major detrimental factor in some geographic areas [23]. A fundamental study about the influence of light intensities on cell performance was published in 2017 by Cojocaru and coworkers [24] where DSC, PSC and $c$-Si cells were compared over a wide range of light intensities and it concludes that PSC is a very promising technology for low-light applications. Based on these and other findings already published, the goal of this work was to contribute further to this topic and to permit a deeper understanding of the advantages of each technology for application in BIPV modules.

\section{Experimental details}

\subsection{Device preparation}

PSC were fabricated according Saliba et al. [25]; preparation details and the testing device are reported elsewhere [26]. With the aid of a mask, the active area was reduced from $0.25 \mathrm{~cm}^{2}$ to $0.20 \mathrm{~cm}^{2}$. The cells were tested with a time interval of $30 \mathrm{~min}$ and stored in inert atmosphere between each measurement. The fabrication of DSC is briefly described in the following. Conducting glass substrates (TEC7, $2.2 \mathrm{~mm}$ thickness, $7 \Omega$ /square from Greatcellsolar ${ }^{\circledast}$, furthermore denoted as transparent conductive oxide (TCO) glasses) were used for working and counter electrodes; for the preparation of the latter, two holes were drilled into the TCO substrate. After thorough substrate cleaning, the Pt catalyst layer (Platisol T/SP, Solaronix ${ }^{\circledR}$ ) was fabricated by doctorblading and subsequent sintering at $450{ }^{\circ} \mathrm{C}$ for $20 \mathrm{~min}$. The photoanode was made by sequential screen-printing of commercial $\mathrm{TiO}_{2}$ pastes: twice 30 NR-D, with a total layer thickness of $(15 \pm 2) \mu \mathrm{m}$ (furthermore denoted as transparent layer) and once 18NR-AO, with a layer thickness of $(9 \pm 2) \mu \mathrm{m}$ (furthermore denoted as scattering layer). Both titania pastes were purchased from Greatcell Solar ${ }^{\circledast}$ and used as received. Substrates with $\mathrm{TiO}_{2}$ films were then sintered at $500{ }^{\circ} \mathrm{C}\left(3{ }^{\circ} \mathrm{C}\right.$ / min) during $1 \mathrm{~h}$. Dye N719 (Ruthenizer 525-bisTBA, CDA, Solaronix ${ }^{\circledast}$, $0.5 \mathrm{mM}$ ) and chenodeoxycholic acid $(5 \mathrm{mM})$ in absolute ethanol were used for sensitization during $24 \mathrm{~h}$. Afterwards, the photoanodes were rinsed with anhydrous acetonitrile, dried in nitrogen flow, sandwiched with the counter-electrode and sealed in a hot-press using a thermoplastic film frame (Surlyn ${ }^{\circledR}$, Meltonix 1170-60, Solaronix ${ }^{\circledast}$ ). Iodine electrolyte (EL-HPE, Greatcellsolar ${ }^{\circledast}$ ) was injected into the cells through the holes in the counter electrode; finally, the injection holes were sealed by Surlyn ${ }^{\circledR}$ and a cover glass using a soldering iron. The cells were equipped with cables to ensure a more stable connection via crocodile clamps to the potentiostat. The photoanodes had a square shape with an area of $0.16 \mathrm{~cm}^{2}$; no mask was used here as no photoactive material had been deposited beyond. For incident angle measurements, lateral sides of both DSC and PSC were darkened to avoid light piping through the glass. No antireflective surface coating was used in either case. Silicon Heterojunction (SHJ) solar cells with a cell area of $4 \mathrm{~cm}^{2}$ were prepared at the Helmholtz Center Berlin, Germany [27]. The surface texturing consists of pyramids (size $2-4 \mu \mathrm{m}$ ) obtained via KOH-based wet chemical etching and a $75 \mathrm{~nm}$ thick ITO front contact, for anti-reflection and improvement of NIR-absorption [5]. An Ag grid covering approximately $3 \%$ of the active cell area was applied by screen printing. The SHJ cells were provided as wafer cutouts and were mounted on a nonconductive glass substrate for better stability. The front contact was equipped with cables on both sides that allowed a simultaneous connection to the potentiostat by using crocodile clamps without damaging the brittle wafer material. The back contact was ensured by silver paint that also served as glue to the nonconductive glass substrate. The SHJ active area of initially $4 \mathrm{~cm}^{2}$ was limited to $3.24 \mathrm{~cm}^{2}$ via a mask.

\subsection{Characterization}

For photoelectrochemical characterization, a $150 \mathrm{~W}$ Oriel class A solar simulator using a 1.5 air mass filter and a MiniSol model LSH7320 Class ABA LED solar simulator (all from Newport, USA) were employed. The effective irradiation intensity was measured in the beginning and at the end of each study with a single crystal Si photodiode (Newport, USA) in case of the class A simulator. All light intensity variation studies were performed on the Class ABA LED simulator that allowed an easy tuning of the light intensity from 1.0 to 0.1 sun. The incident angle was modified manually with the aid of a rotation stage, while $\theta_{O}\left(\right.$ at $0^{\circ}$ ) corresponds to perpendicular irradiation. $I$ - $V$ curves were recorded with a potentiostat (Zennium, Zahner-Elektrik $\mathrm{GmbH}$, Germany) at a scan rate of $10 \mathrm{mV} / \mathrm{s}$ for PSC and $50 \mathrm{mV} / \mathrm{s}$ for DSC and SHJ cells in backward scan direction. At the end of each study, every cell was measured again at the initial condition (at $\theta_{0}$ or under 1.0 sun) to ensure that the cell had not evolved. As a consequence, cells with more than $5 \%$ derivation from the initial efficiency were discarded. Each test was performed with 4 or at least 2 samples. Scanning electron microscope (SEM) images were recorded with a Quanta 400 FEG (FEI, USA) at the CEMUP materials analysis center of the University of Porto.

\section{Results and discussion}

\subsection{Incident angle study}

In a first time, $I-V$ curves were recorded for all three cell types (Table 1) and normalized average efficiencies were analyzed as a function of the incident angle irradiation (Fig. 1a). SHJ and perovskite cells follow both a $\cos (\theta)$ curve for simple geometric light power density reduction at higher inclination angles [28]. This is remarkable as no surface treatment was applied on PSC (while the SHJ cells had received an anti-reflector etching treatment), and can be explained by the lower refractive index ( 2.49 for $\mathrm{TiO}_{2}$ anatase and 2.43 for methylammonium lead iodide perovskite [29]) compared to 3.98 for silicon [30]. As a consequence, PSC fabrication does not require additional and thus costraising antireflective surface modifications. In fact, only ca. $10 \%$ of commercial $\mathrm{Si}$ modules are equipped with antireflective protection glass, mainly for high efficiency installations [31]. DSC exhibit an increased efficiency at intermediate angles between $15^{\circ}$ and $45^{\circ}$ that directly reflects in the corresponding current density (Fig. 1b). Refractive indexes in DSC can be considered similar to that of PSC, as both cells employ anatase $\mathrm{TiO}_{2}$ atop TCO substrates. Consequently, the peculiar behavior of DSC is not due to the refractive index of the cell system. Toyoda et al. observed such effect as well and referred it to the

Table 1

Efficiencies and $I-V$ characteristics of the best cell and average values of DSC, PSC and SHJ cells.

\begin{tabular}{lllll}
\hline Cell type & $J_{\mathrm{SC}} / \mathrm{mA} \mathrm{cm}^{-2}$ & $V_{\mathrm{OC}} / \mathrm{V}$ & $\mathrm{FF}$ & $\eta / \%$ \\
\hline DSC (best cell) & 17.15 & 0.71 & 0.73 & 8.9 \\
DSC (average) & 15.68 & 0.70 & 0.73 & $8.3 \pm 0.5$ \\
PSC (best cell) & 20.23 & 1.05 & 0.73 & 15.4 \\
PSC (average) & 20.50 & 1.04 & 0.69 & $14.8 \pm 0.5$ \\
SHJ (best cell) & 36.56 & 0.71 & 0.73 & 18.9 \\
SHJ (average) & 36.61 & 0.71 & 0.71 & $18.4 \pm 0.5$ \\
\hline
\end{tabular}



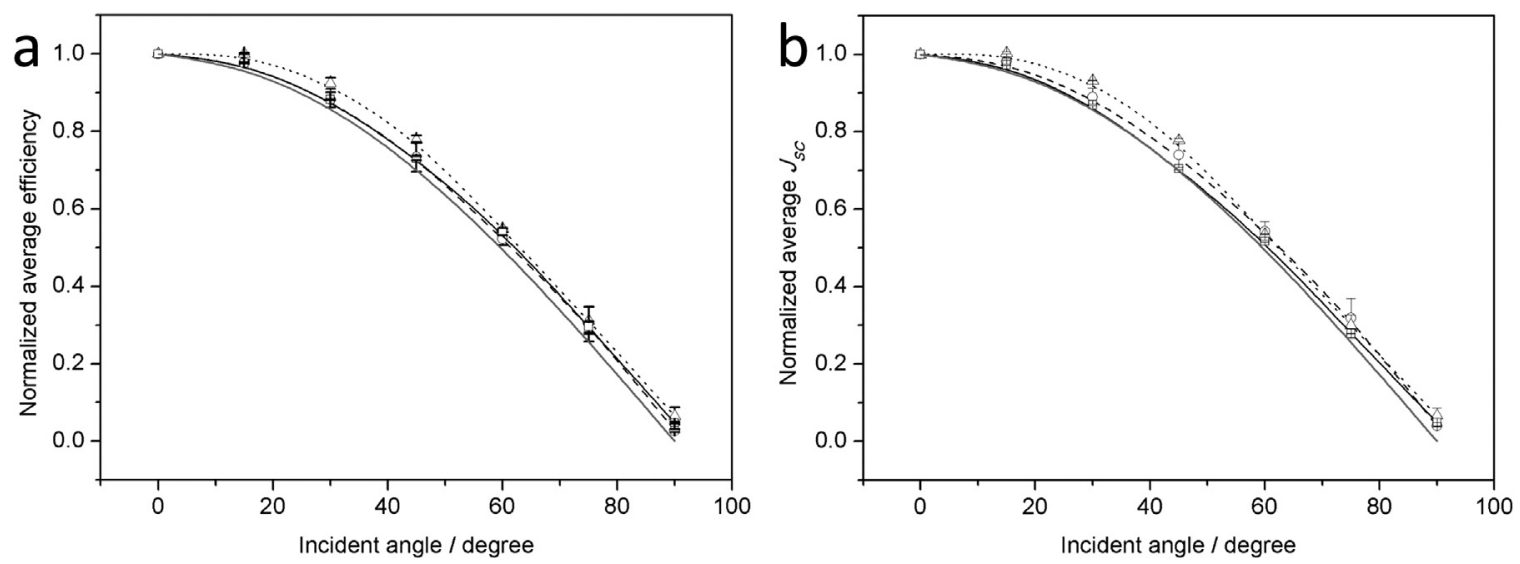

Fig. 1. (a) Normalized average efficiencies of SHJ cell (squares with solid line), PSC (circles with dashed line) and DSC (triangles with dotted line) as a function of incident angle. The grey line represents a plotted $\cos (\theta)$ function. (b) Corresponding current densities.
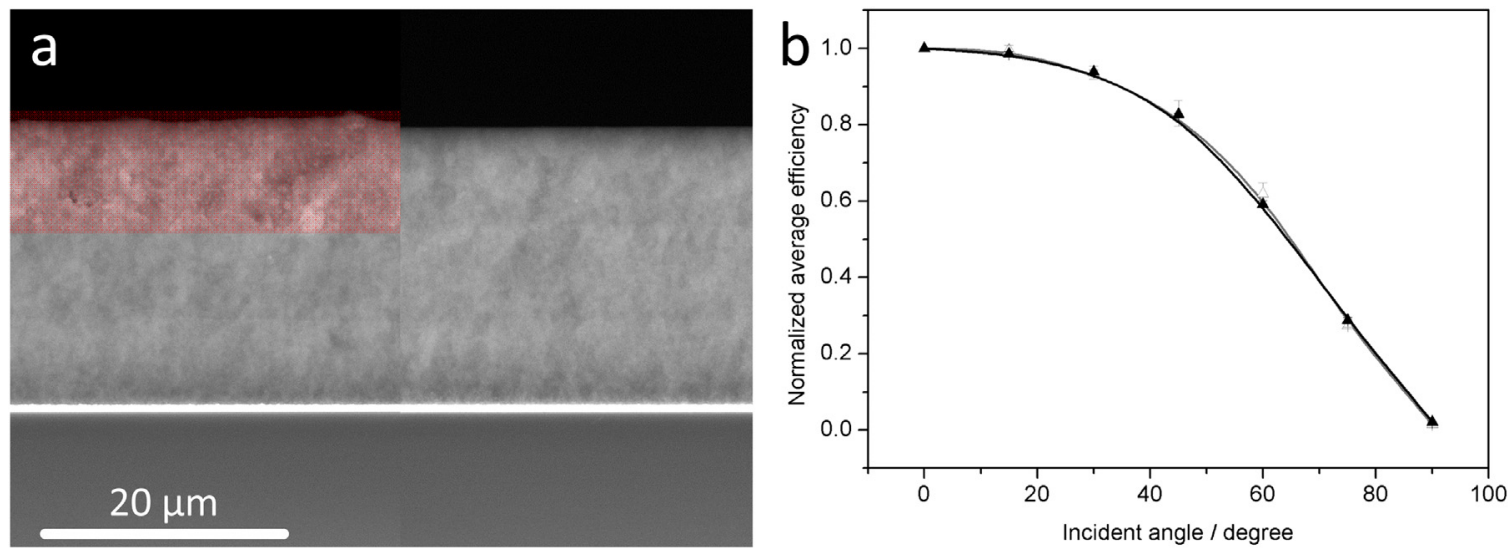

Fig. 2. (a) Cross section of screen-printed DSC photoanodes. Left: standard configuration (with 2 layers of transparent $\mathrm{TiO}_{2}$ and one scattering layer atop (red area)), reaching a total thickness of $23 \mu \mathrm{m}$; right: with 3 printed transparent $\mathrm{TiO}_{2}$ layers, showing corresponding thickness (22 $\left.\mu \mathrm{m}\right)$. (b) Normalized average efficiency of DSC with standard configuration ( 2 transparent and 1 scattering $\mathrm{TiO}_{2}$ layer, black triangles) and DSC without scattering layer but of similar TiO ${ }_{2}$ thickness (grey empty triangles).

micrometer-thick $\mathrm{TiO}_{2}$ scattering layer, whose optical properties are thought to increase light absorption at higher incident angles [32]. To test if the assumption of Toyoda et al. was correct, DSC without scattering layer were fabricated and analyzed. For better comparability, the active layer thickness was maintained by substituting the scattering layer by a third transparent screen-printed $\mathrm{TiO}_{2}$ layer (Fig. 2a). The subsequent incident angle study revealed that absolutely no difference occurred between the DSC with and without scattering layer (Fig. 2b) and therefore, the scattering layer cannot originate the phenomenon observed in Fig. 1. It can be concluded that the scattering layer enhances cell efficiency at $\theta_{O}$ (from $(6.5 \pm 0.3) \%$ to $(8.4 \pm 0.4) \%$ ), but did not improve cell performance at higher incident angles.

In a study performed by D'Ercole et al., DSC with different $\mathrm{TiO}_{2}$ transparent layer thicknesses were compared. They observed a tiny relative increase in efficiencies at intermediate angles that depends on the active layer thickness, with thinner $\mathrm{TiO}_{2}$ layers $(3 \mu \mathrm{m}$ instead of $13 \mu \mathrm{m}$ ) leading to higher relative increase than thicker layers. The authors arrive to the conclusion that optical path lengthening upon inclination becomes more important for thinner and thus more transparent cells. On the contrary, thicker cells suffer principally from light power density reduction upon inclination, which results in a more cosine-shaped behavior [33]. It was decided to verify these findings with an even higher variety of DSC architectures to find out what causes DSC to show a higher than $\cos (\theta)$ evolution. As standard configuration, DSC generally employ two screen-printed transparent $\mathrm{TiO}_{2}$ layers and one scattering layer, reaching a total active layer thickness of $23 \mu \mathrm{m}$. As earlier test showed that the $\mathrm{TiO}_{2}$ scattering layer merely increases cell efficiency under standard conditions, all DSC employed only transparent layers for simplicity reasons. DSC with $\mathrm{TiO}_{2}$ layers of 3,7 and $15 \mu \mathrm{m}$ were fabricated by screen-printing and tested at various incident angles (Fig. 3). Indeed, slightly superior efficiencies are observed for DSC with $3 \mu \mathrm{m}$ photoanode thickness, but a closer look on the current density comparison reveals that they actually do not differ from standard cells. Actually, these DSC solely show a slightly increased fill factor and $V_{\mathrm{OC}}$ at higher angles that combined lead to superior efficiencies (Fig. $3 \mathrm{c}$ and $\mathrm{d}$ ).

This means that optical path lengthening did not increase for thinner DSC, as stronger light absorption would directly reflect in higher current density. Perovskite photoanodes show close to zero transmission from 300 to around $550 \mathrm{~nm}$, merely reaching $26 \%$ at $725 \mathrm{~nm}$ (Fig. 4). That means that sample inclination cannot yield increased light path and thus improved light absorption, which is why a cosine-like efficiency evolution upon sample inclination is obtained (Fig. 1). According to this thesis though, normalized efficiencies higher than $\cos (\theta)$ should be obtained if the transmittance of the photoactive film increases. To check this assumption, more transparent perovskite layers were fabricated by spin-coating of precursor solutions that were diluted in DMF, while the $\mathrm{TiO}_{2}$ layer remained without any modification. Two different films were studied: a 1:2 vol fraction dilution, furthermore denoted as dilution $\# 1$, and a 1:5 vol fraction dilution, furthermore denoted as dilution \#2. Transmission spectra of the photoactive layer show an increase in transmittance according to the 

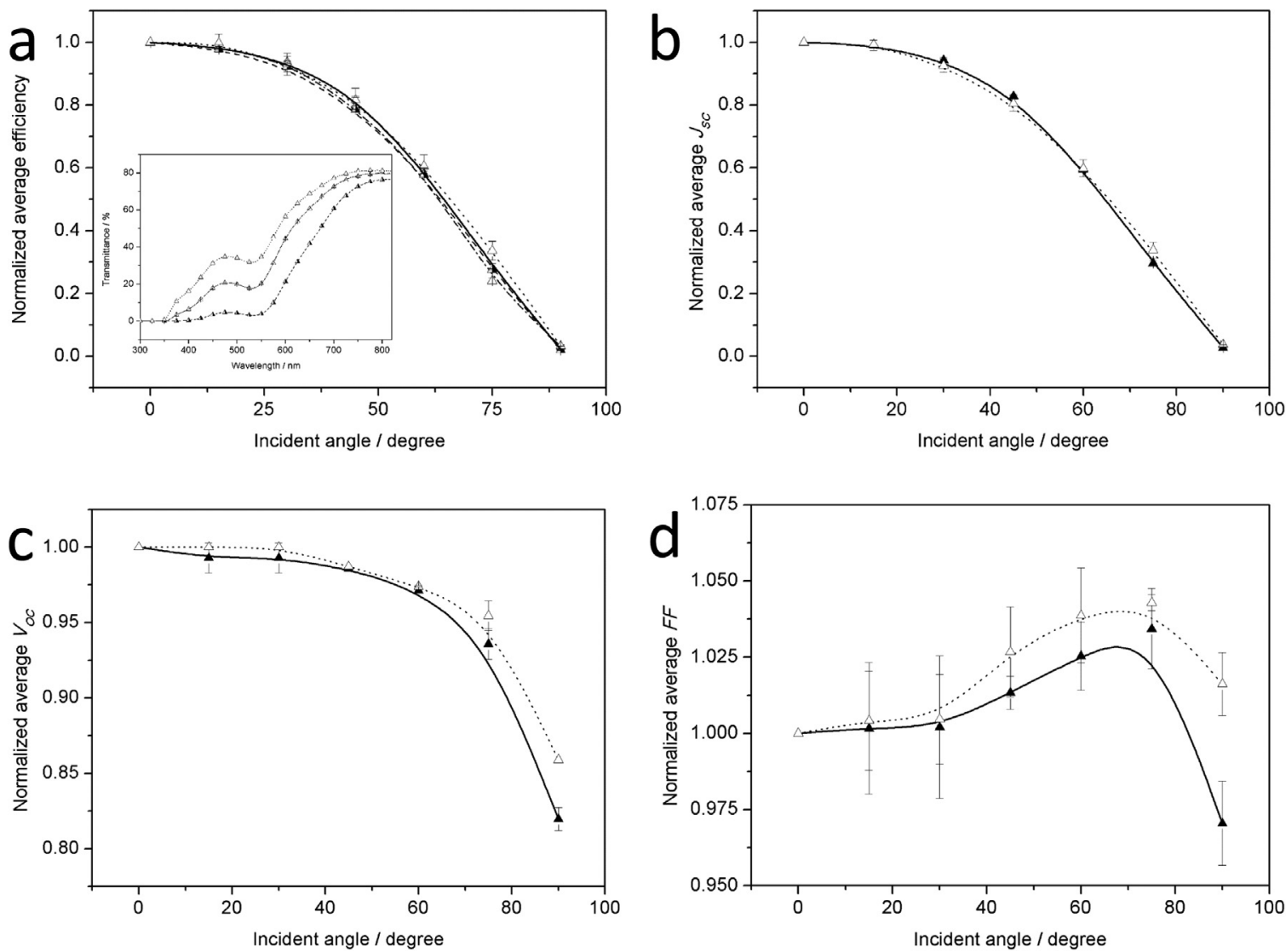

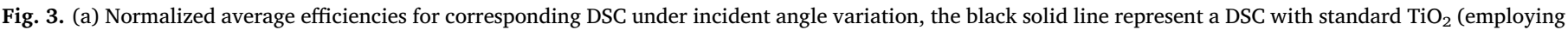

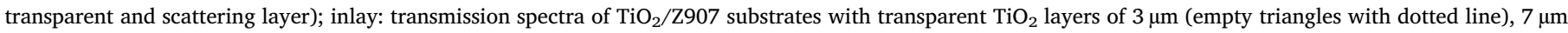

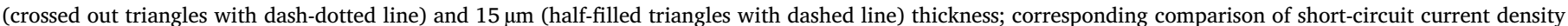

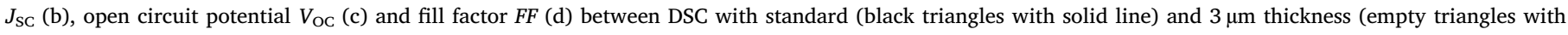
dotted line).

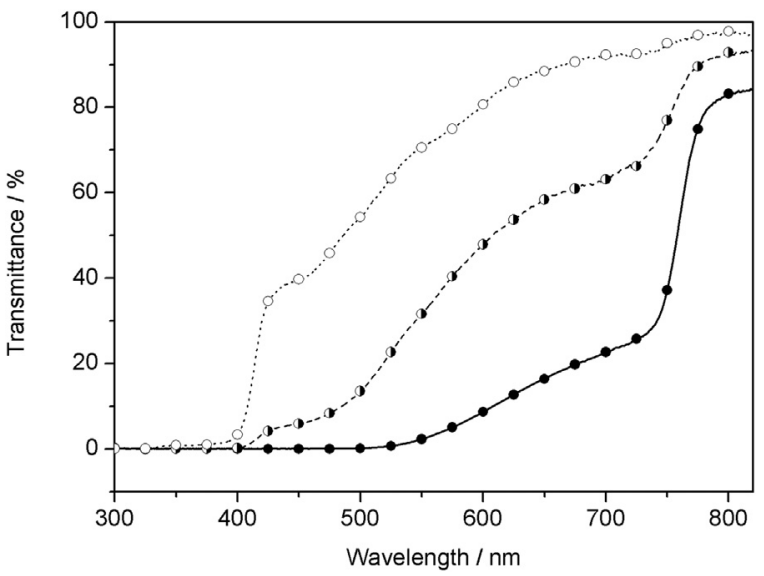

Fig. 4. Transmission spectra of perovskite films made from precursor solutions with standard concentration (black circles with solid line), dilution \#1 (halffilled circles with dashed line) and dilution \#2 (empty circles with dotted line), on top of $\mathrm{TiO}_{2}$ substrates.

precursor dilution degree (Fig. 4). Absorbance below $400 \mathrm{~nm}$ was attributed to $\mathrm{TiO}_{2}$ and therefore the transmittance in this wavelength range did not change along the different films. Cross section SEM images of PSC fabricated with such films show that the capping layer reduces from 250 to $70 \mu \mathrm{m}$ for dilution $\# 1$ and disappears when perovskite was fabricated with dilution \#2 (Fig. 5).

Subsequently, these films were tested in PSC under incident angle variation (Fig. 6a). Indeed, normalized efficiencies higher than $\cos (\theta)$ at medial incident angles were obtained for both more transparent perovskite films, even higher than those of standard DSC. Among PSC, higher relative efficiencies were obtained for dilution \#1; for PSC with even more transparent active layers (obtained from dilution \#2), a very similar yet slightly less increased evolution was obtained. Fig. $6 \mathrm{~b}$ shows that the current density evolution under incident angle modification follows the same tendency as the cell efficiencies. Therefore, the $>\cos$ $(\theta)$ phenomenon can indeed be attributed to optical path lengthening here. Obviously, cell efficiencies drop when more transparent active layers are used. In the present case, efficiencies dropped from $(14.2 \pm 0.7) \%$ for standard cells to $(6.2 \pm 0.5) \%$ for PSC with dilution \#1 and to $(4.1 \pm 0.2) \%$ for dilution \#2. However, in buildingintegrated applications where transparency may be preferred over high efficiencies, the increased tolerance towards incident angle of these thinner PSC might be a welcome plus to consider. Regarding DSC, the conclusion to be drawn is that the $>\cos (\theta)$ behavior for standard cells already implies optical path lengthening, comparable to PSC obtained from diluted precursor solutions. As the molar attenuation coefficient of dyes such as N719 is one order of magnitude lower than that of methylammonium lead iodide perovskites [34], it was not reasonable to fabricate a DSC with sufficient $\mathrm{TiO}_{2}$ thickness to exhibit a true $\cos (\theta)$ efficiency evolution (similar to PSC with complete light absorption) for the negative test. In that case, the increased series resistance due to a longer electron diffusion path would have substantially changed the photoelectrochemical properties of the entire system [35]. Therefore, DSC lag behind PSC and SHJ in terms of light absorption capacities, which is reflected in the higher than $\cos (\theta)$ evolution of Fig. 1.

Obviously, a top glass for protection of mechanic impacts and atmospheric factors has to be applied in BIPV façades and envelopes, 


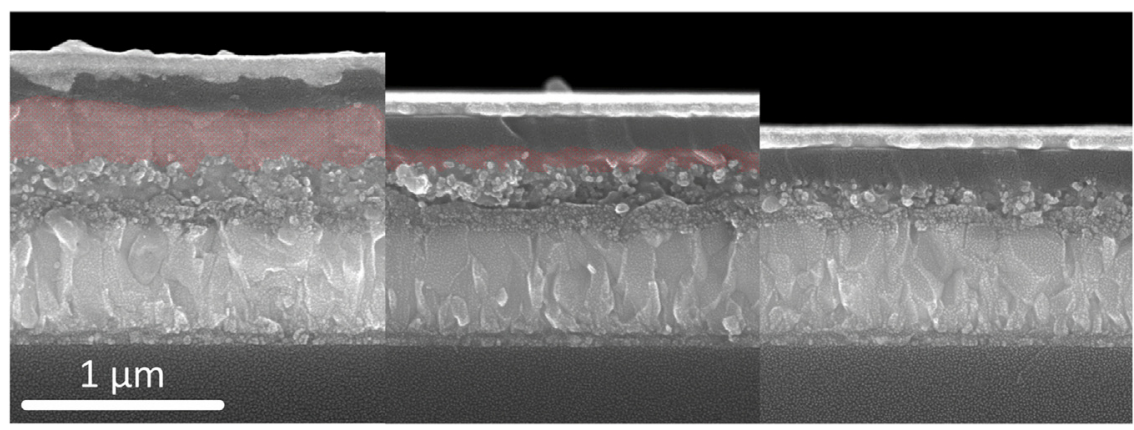

Fig. 5. Cross section of PSC obtained from different perovskite precursor solution concentrations. Left: standard concentration, yielding a perovskite capping layer of circa $250 \mathrm{~nm}$ (red area); middle: obtained from dilution \#1, resulting in a circa $70 \mathrm{~nm}$ capping layer (red area); right: obtained from dilution \#2, showing no visible capping layer.

which then will interfere with incident light angle through surface and interface reflections. However, all cell types require such extra glass housing for the end application and as such, it was beyond the scope of this work to determine optimum housing-cell distances and antireflective coatings.

\subsection{Light intensity variation}

Photovoltaic installations are subjected to different irradiation intensities along the day and weather conditions. According to Kalogirou, $80 \%$ of the daily irradiation hits the earth with intensities between 1 and 0.1 sun [36], which is why it was decided to focus the study on this range of intensities. All cell types were tested and the relative efficiencies are displayed in Fig. 7a. Until 0.4 sun, all systems maintain more than $90 \%$ of their initial efficiency but from 0.25 sun on, DSC and PSC begin to decrease while SHJ cells continue to deliver efficiencies that turn around $90 \%$. The test was repeated several times and it was performed with all modified DSC and PSC systems previously used for the incident angle study, but the tendencies remained always very similar. Merely, DSC with the $3 \mu \mathrm{m}$ thick $\mathrm{TiO}_{2}$ transparent layer performed slightly better than the standard cells, showing a similar curve as standard PSC.

In the literature, it is commonly accepted that DSC are better light harvester when it comes to lower light intensities [32,37]. M. McGehee, though, argues that such properties are principally obtained when DSC use cobalt or copper redox pairs instead of iodine [38]. Although having better band alignment, such cobalt or copper-based DSC are limited by low diffusion rates at high light intensities, which translates by an increased series resistance [39]. Consequently, efficiencies raise when lower light intensities hit the cell since lower diffusion rates of the redox pair become negligible for overall cell efficiency [40]. Within this logic and by developing an optimized dye system for efficient light uptake at lower intensities, Freitag and coworkers achieved a power- conversion efficiency (PCE) of $28.9 \%$ under indoor illumination [13]. Simultaneously, PSC optimization for dim light yielded a PCE of $26.3 \%$ [41]. Cojocaru and coworkers published a study of light intensities ranging from $10^{2}$ to $10^{-3} \mathrm{~mW} \mathrm{~cm}^{-2}$, where they evidence that the relatively higher efficiencies of DSC and PSC at very low intensities (below $10^{-2} \mathrm{~mW} \mathrm{~cm}^{-2}$ ) are due to internal capacitive phenomena at the interfaces that lead to an overestimation of the effective efficiencies [24]. Hinsch et al. studied entire DSC modules under outdoor conditions, and they also observed better performance for DSC at lower light intensities in comparison to $a$-Si and CIGS. Furthermore, they clearly identify the determining factor, namely a low fill factor at high light intensities that grows under light intensity reduction; current density is linear to the light intensity and the photovoltage decreases similarly in all cases [37]. In our case, short-circuit current density also drops linearly with light intensity, which is in agreement with the literature [42,43]. Only at intensities of 0.25 sun and smaller, a small deviation from the linear curve is observed for DSC and PSC, which might be an indication that charge collection efficiency is slightly downgraded here (Fig. 7b). The Fermi level and thus the open circuit potential decrease under reduced light flux $[44,45]$, while the degree of the influence depends on the nature of the semiconductor [46]. This might explain little deviations between the cell types in Fig. $7 \mathrm{c}$. The performance variable more affected is the normalized fill factor, which increases up to 1.11 for SHJ, while it remains much more constant for DSC and PSC (Fig. 7d). Comparison of the standard $I-V$ results from the Helmholtz institute with ours reveal that all performance variables are lower, that is $J_{\mathrm{SC}}$ (circa less $2 \mathrm{~mA} / \mathrm{cm}^{2}$ ), $V_{\mathrm{OC}}$ (circa less $100 \mathrm{mV}$ ) but above all the fill factor values ( $>0.78$ against 0.73 ). This is an indication for added series resistances, likely arising from the testing setup. Therefore, the increasing $F F$, which is the principal reason for the higher relative efficiencies at lower light intensities, could be at least partially due to reduced series resistance at lower electron flux, similarly to the mechanism described for the cobalt or copper based DSC mentioned
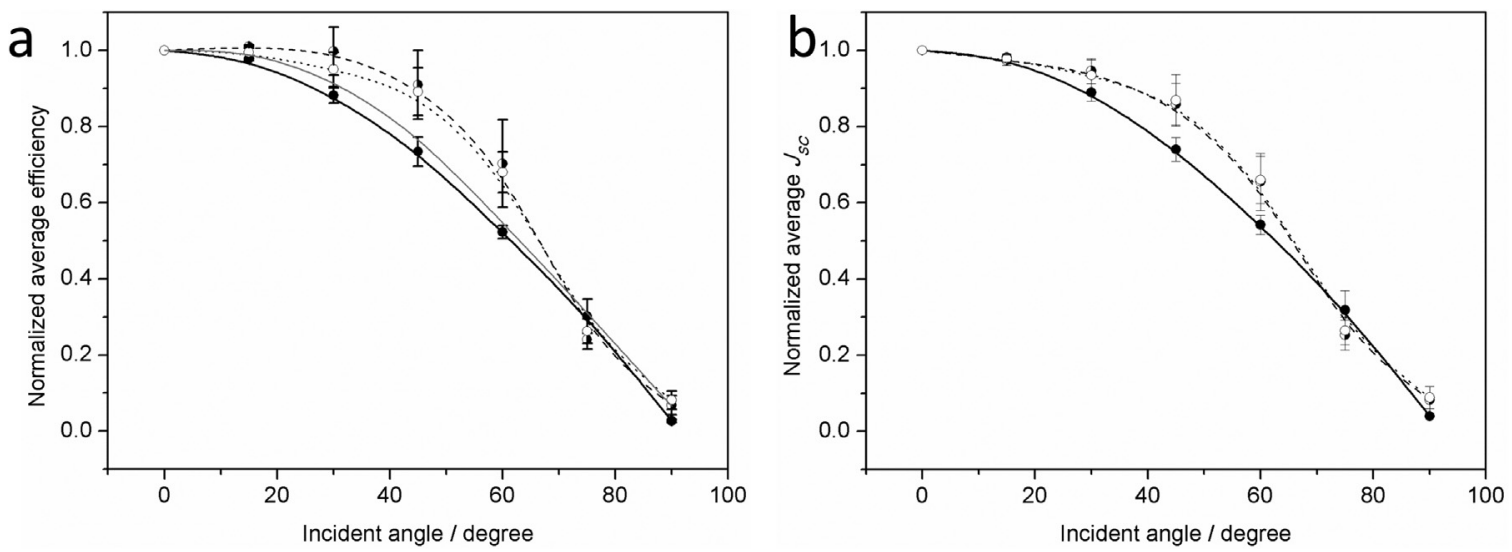

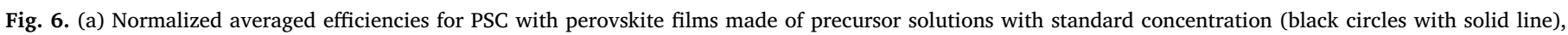

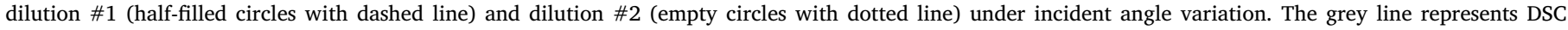
response from Fig. 1 for comparison. (b) Corresponding short-circuit current density $J_{\text {SC. }}$ 

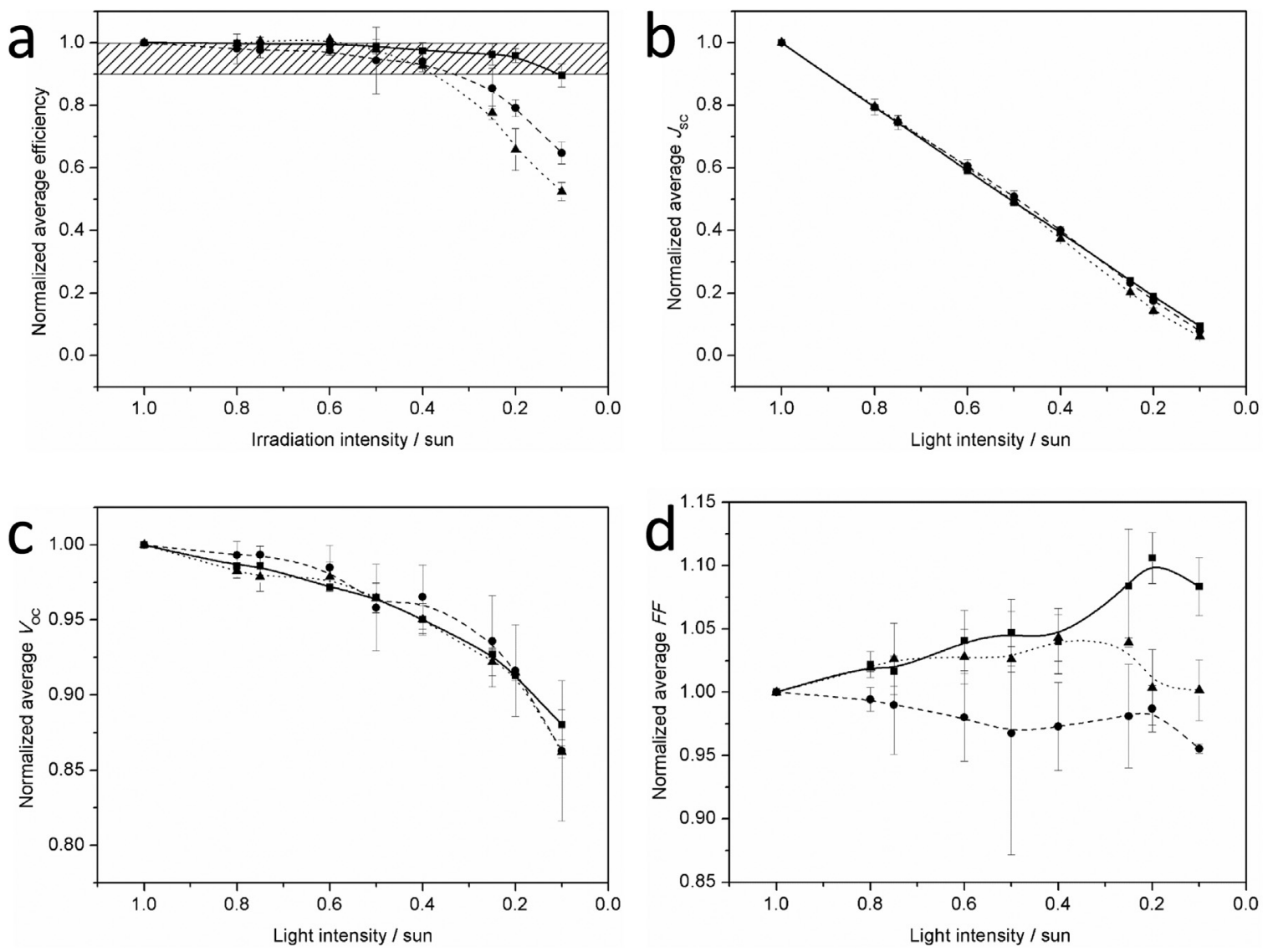

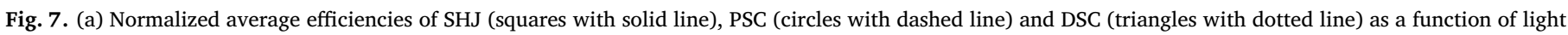

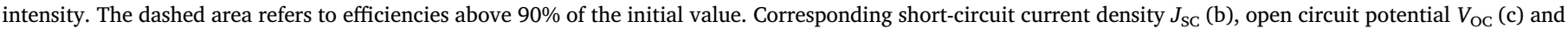
fill factor $F F($ d).

before. Nevertheless, there is room to believe that SHJ solar cells are a good candidate for low-light applications, as the charge separation is more efficient thanks to the wide-bandgap buffer layer that functions as semi-permeable charge carrier extracting membrane. The technologies tested here are situated at different product development stages, with different active areas and interface engineering. This is why a reliable comparison of the technologies remains always limited, as the present study compares the modifications of the average cell efficiencies that are normalized to the active cell area. The cell efficiency, nonetheless, is affected by recombination events not only at the cell interfaces, but also at the cell boundaries that have a bigger fraction of the cell area in the case of smaller cells.

\section{Conclusion and outlook}

In this work, DSC, PSC and SHJ solar cells as potential candidates for incorporation BIPV modules were compared in terms of efficiency under different incident angles and light intensities. By varying the cell architecture of DSC and PSC, optical path lengthening due to incomplete light absorption at $\theta_{0}$ was ascertained as cause for the higher than $\cos (\theta)$ evolution of the normalized efficiencies in DSC under different incident angles. The $\mathrm{TiO}_{2}$ scattering layer as possible source was ruled out. It was possible to induce the same behavior in more transparent PSC that were obtained by deposition of a diluted precursor solution, thus reducing the thickness of the active layer. Although exhibiting lower overall performance, such cells are less prone to incident angle-induced efficiency losses at intermediate angles (from $0^{\circ}$ to $70^{\circ}$ ). This behavior might become interesting for building-integrated concepts, where transparency is favored over high efficiencies. SHJ cells were found to follow a geometric $\cos (\theta)$ curve due to light power density reduction, similar to standard PSC. It is remarkable that even without application of any anti-reflective layer and due to favorable refractive indexes, PSC and DSC rival SHJ cells, this last equipped with antireflective micropyramids on the surface. This extra step potentially increases cell fabrication costs and is therefore an economic advantage for the two former technologies. As a next step, the study should be complemented with an optimization of a protective glass envelope in terms of sample-glass topper distance and surface reflections.

Light intensity reduction revealed that all cell types perform fairly well, maintaining $90 \%$ of their initial efficiency up to and including 0.4 sun. At even lower intensities, PSC were found to slightly outperform DSC. The DSC used for these study employed iodide/triiodide as redox pair and showed similar tendencies to those published by Cojocaru et al. [24]. However, DSC with better efficiencies at lower light intensity generally employ copper or cobalt based redox pairs. Indeed, such DSC are an ongoing topic in our laboratory to pursue this study. SHJ revealed a quite surprising efficiency evolution over the light intensity range tested, which may be in part due to series resistances resulting from the testing device under standard configuration. Even so, SHJ hold great promise for stable efficiencies under lower light intensities due to their cell architecture. Unlike in $c$-Si solar cells, charge carriers are efficiently separated by the wide-bandgap intrinsic $a$-Si:H passivation layer, which should decrease recombination phenomena that become predominant at low light intensities. Altogether, SHJ solar cells seem to be promising candidates within silicon solar cells for building-integrated solutions and surprisingly, no published work addresses this topic, to the best of our knowledge. Therefore, an improved study over a wider range of light intensities and with a more suitable testing setup is matter of ongoing research.

Briefly, perovskite solar cells show excellent properties for building- 
integrated applications, with the possibility to tune their transparency and thus optical properties, simply by diluting the perovskite precursor solution. Dye-sensitized solar cells are often considered the showcase model for building-integrated solutions, due to their higher than $\cos (\theta)$ efficiency evolution under tilted angle and enhanced performance at lower light intensities that is, yet, true for DSC that employ redox pairs exhibiting intrinsic series resistances under standard conditions. Both features could be obtained in a similar way or even better with the two other cell types. Finally, silicon heterojunction solar cells hold great promise for building-integrated concepts as they unite the advantages of c-Si cells (low toxicity, material abundance and stability) with a high $V_{\text {OC }}(>700 \mathrm{mV}$ ), cell efficiencies currently reaching 26.6\% [47] and the very low material consumption due to the use of very thin film $s$.

\section{Acknowledgement}

The authors acknowledge the European Commission through the Seventh Framework Programme, the Specific Program "Ideas" of the European Research Council for research and technological development as part of an Advanced Grant under Grant Agreement No. 321315 (BIDSC). L. Andrade is grateful to FCT (Fundação para a Ciência e a Tecnologia) for funding (IF/01331/2015). This work was partially supported by the European Union's Horizon 2020 Programme, through a FET Open research and innovation action under grant agreement No 687008. The authors also acknowledge the Projects: i) POCI-01-0145FEDER-006939 (LEPABE - Laboratory for Process Engineering, Environment, Biotechnology and Energy - UID/EQU/00511/2013), funded by the European Regional Development Fund (ERDF), through COMPETE2020 - Programa Operacional Competitividade e Internacionalização (POCI) and by nationals funds through FCT and ii) NORTE-01-0145-FEDER-000005 - LEPABE-2-ECO-INNOVATION, supported by North Portugal Regional Operational Programme (Norte 2020), under the Portugal 2020 Partnership Agreement, through the European Regional Development Fund (ERDF). R. Arnaldo and F. Santos are thanked for sample preparation.

\section{References}

[1] R.A. Betts, C.D. Jones, J.R. Knight, R.F. Keeling, J.J. Kennedy, El Nino and a record $\mathrm{CO}_{2}$ rise, Nat. Clim. Change 6 (2016) 806-810.

[2] R. Lacal Arantegui, A. Jäger-Waldau, Photovoltaics and wind status in the European Union after the Paris agreement, Renew. Sustain. Energy Rev. 81 (2018) $2460-2471$.

[3] Z.V. Michiel Ritzen, Chris Geurts, Building integrated photovoltaics, Photovolt. Energy (2017).

[4] E. Biyik, M. Araz, A. Hepbasli, M. Shahrestani, R. Yao, L. Shao, E. Essah, A.C. Oliveira, T. del Caño, E. Rico, J.L. Lechón, L. Andrade, A. Mendes, Y.B. Atlı, A key review of building integrated photovoltaic (BIPV) systems, Eng. Sci. Technol. Int. J. 20 (2017) 833-858.

[5] S. De Wolf, A. Descoeudres, C. Holman Zachary, C. Ballif, High-efficiency Silicon Heterojunction Solar Cells: A Review, in: green, 2012, pp. 7.

[6] A. Louwen, W. van Sark, R. Schropp, A. Faaij, A cost roadmap for silicon heterojunction solar cells, Sol. Energy Mater. Sol. Cells 147 (2016) 295-314.

[7] A. Asghar, M. Emziane, H.K. Pak, S.Y. Oh, Outdoor testing and degradation of dyesensitized solar cells in Abu Dhabi, Sol. Energy Mater. Sol. Cells 128 (2014) 335-342.

[8] J. Maçaira, L. Andrade, A. Mendes, Laser sealed dye-sensitized solar cells: efficiency and long term stability, Sol. Energy Mater. Sol. Cells 157 (2016) 134-138.

[9] S. Yoon, S. Tak, J. Kim, Y. Jun, K. Kang, J. Park, Application of transparent dyesensitized solar cells to building integrated photovoltaic systems, Build. Environ. 46 (2011) 1899-1904.

[10] R. Corrao, G. Milia, M. Morini, L. Pastore, C. Tutone, Benefits of a translucent building envelope made of DSC-integrated glass blocks, in, Economic Forum, pp. 18-27-18-27.

[11] J.-G. Kang, J.-H. Kim, J.-T. Kim, Performance Evaluation of DSC Windows for Buildings, Int. J. Photo. 2013 (2013) 6.

[12] K. Kalyanasundaram, Dye-Sensitized Solar Cells, EPFL Press, 2010, p. 320 https:// www.crcpress.com/Dye-sensitized-Solar-Cells/Kalyanasundaram/p/book/ 9781439808665.

[13] M. Freitag, J. Teuscher, Y. Saygili, X. Zhang, F. Giordano, P. Liska, J. Hua, S.M. Zakeeruddin, J.-E. Moser, M. Grätzel, A. Hagfeldt, Dye-sensitized solar cells for efficient power generation under ambient lighting, Nat. Photonics 11 (2017) 372.

[14] K. Kawata, K. Tamaki, M. Kawaraya, Dye-sensitised and perovskite solar cells as indoor energy harvestors, J. Photopolym. Sci. Technol. 28 (2015) 415-417.
[15] H.-S. Kim, C.-R. Lee, J.-H. Im, K.-B. Lee, T. Moehl, A. Marchioro, S.-J. Moon, R. Humphry-Baker, J.-H. Yum, J.E. Moser, M. Grätzel, N.-G. Park, Lead iodide perovskite sensitized all-solid-state submicron thin film mesoscopic solar cell with efficiency exceeding 9\%, Sci. Rep. 2 (2012) 591.

[16] Renewable Energy - Market and Policy Trends in IEA Countries, International Energy Agency, 2004.

[17] R.K. Misra, S. Aharon, B. Li, D. Mogilyansky, I. Visoly-Fisher, L. Etgar, E.A. Katz, Temperature- and Component-dependent degradation of perovskite photovoltaic materials under concentrated sunlight, J. Phys. Chem. Lett. 6 (2015) 326-330.

[18] M.C. Harry, K.D.G.I. Jayawardena, S. Zlatka, S. Maxim, S.R.P. Silva, Effects of ambient humidity on the optimum annealing time of mixed-halide Perovskite solar cells, Nanotechnology 28 (2017) 114004

[19] D. Wang, M. Wright, N.K. Elumalai, A. Uddin, Stability of perovskite solar cells, Sol. Energy Mater. Sol. Cells 147 (2016) 255-275.

[20] I. Mesquita, L. Andrade, A. Mendes, Perovskite solar cells: materials, configurations and stability, Renew. Sustain. Energy Rev. 82 (2018) 2471-2489.

[21] M. Girolamo, P.A. L, D.C. Aldo, B.T. M, Laser processing in the manufacture of dye-sensitized and perovskite solar cell technologies, ChemElectroChem 3 (2016) 9-30.

[22] S. Emami, J. Martins, L. Andrade, J. Mendes, A. Mendes, Low temperature hermetic laser-assisted glass frit encapsulation of soda-lime glass substrates, Opt. Lasers Eng. 96 (2017) 107-116.

[23] I. Geisemeyer, N. Tucher, B. Müller, H. Steinkemper, J. Hohl-Ebinger, M.C. Schubert, W. Warta, Angle Dependence of solar cells and modules: the role of cell texturization, IEEE J. Photovolt. 7 (2017) 19-24.

[24] L. Cojocaru, S. Uchida, K. Tamaki, P.V.V. Jayaweera, S. Kaneko, J. Nakazaki, T. Kubo, H. Segawa, Determination of unique power conversion efficiency of solar cell showing hysteresis in the I-V curve under various light intensities, Sci. Rep. 7 (2017) 11790.

[25] M. Saliba, T. Matsui, J.-Y. Seo, K. Domanski, J.-P. Correa-Baena, M.K. Nazeeruddin, S.M. Zakeeruddin, W. Tress, A. Abate, A. Hagfeldt, M. Gratzel, Cesium-containing triple cation perovskite solar cells: improved stability, reproducibility and high efficiency, Energy Environ. Sci. 9 (2016) 1989-1997.

[26] V. Stockhausen, I. Mesquita, L. Andrade, A. Mendes, Insights in perovskite solar cell fabrication: unraveling the hidden challenges of each layer, IEEE J. Photovolt. (2018) 1-10.

[27] A.M.-.V.M. Hendrichs, L. Mazzarella, S. Kirner, M. Zelt, H. Rhein, S. Calnan, L. Korte, B. Stannowski, R. Schlatmann, 2AV.2.29 process development for silicon heterojunction solar cells, in: Proceedings of the EU PVSEC, Munich, Germany, 2016.

[28] J.M. Ball, S.D. Stranks, M.T. Horantner, S. Huttner, W. Zhang, E.J.W. Crossland, I. Ramirez, M. Riede, M.B. Johnston, R.H. Friend, H.J. Snaith, Optical properties and limiting photocurrent of thin-film perovskite solar cells, Energy Environ. Sci. 8 (2015) 602-609.

[29] L.J. Phillips, A.M. Rashed, R.E. Treharne, J. Kay, P. Yates, I.Z. Mitrovic, A. Weerakkody, S. Hall, K. Durose, Dispersion relation data for methylammonium lead triiodide perovskite deposited on a (100) silicon wafer using a two-step vapour-phase reaction process, Data Brief. 5 (2015) 926-928.

[30] D.E. Aspnes, A.A. Studna, Dielectric functions and optical parameters of Si, Ge, GaP, GaAs, GaSb, InP, InAs, and InSb from 1.5 to $6.0 \mathrm{eV}$, Phys. Rev. B 27 (1983) 985-1009.

[31] in.

[32] T. Toyoda, T. Sano, J. Nakajima, S. Doi, S. Fukumoto, A. Ito, T. Tohyama, M. Yoshida, T. Kanagawa, T. Motohiro, T. Shiga, K. Higuchi, H. Tanaka, Y. Takeda, T. Fukano, N. Katoh, A. Takeichi, K. Takechi, M. Shiozawa, Outdoor performance of large scale DSC modules, J. Photochem. Photobiol. A Chem. 164 (2004) 203-207.

[33] D. D'Ercole, L. Dominici, T.M. Brown, F. Michelotti, A. Reale, A.D. Carlo, Angular response of dye solar cells to solar and spectrally resolved light, Appl. Phys. Lett. 99 (2011) 213301.

[34] J.-H. Im, C.-R. Lee, J.-W. Lee, S.-W. Park, N.-G. Park, 6.5\% efficient perovskite quantum-dot-sensitized solar cell, Nanoscale 3 (2011) 4088-4093.

[35] P. Selvaraj, H. Baig, T.K. Mallick, J. Siviter, A. Montecucco, W. Li, M. Paul, T. Sweet, M. Gao, A.R. Knox, S. Sundaram, Enhancing the efficiency of transparent dye-sensitized solar cells using concentrated light, Sol. Energy Mater. Sol. Cells 175 (2018) 29-34.

[36] S.A. Kalogirou, Chapter 2 - Environmental characteristics, Solar Energy Engineering, 2nd ed., Academic Press, Boston, 2014, pp. 51-123.

[37] A. Hinsch, H. Brandt, W. Veurman, S. Hemming, M. Nittel, U. Würfel, P. Putyra, C. Lang-Koetz, M. Stabe, S. Beucker, K. Fichter, Dye solar modules for facade applications: recent results from project ColorSol, Sol. Energy Mater. Sol. Cells 93 (2009) 820-824.

[38] M.D. McGehee, Paradigm shifts in dye-sensitized solar cells, Science 334 (2011) 607-608.

[39] Y. Bai, Q. Yu, N. Cai, Y. Wang, M. Zhang, P. Wang, High-efficiency organic dyesensitized mesoscopic solar cells with a copper redox shuttle, Chem. Commun. 47 (2011) 4376-4378.

[40] K. Kakiage, Y. Aoyama, T. Yano, K. Oya, J.-i. Fujisawa, M. Hanaya, Highly-efficient dye-sensitized solar cells with collaborative sensitization by silyl-anchor and carboxy-anchor dyes, Chem. Commun. 51 (2015) 15894-15897.

[41] C. Chien-Yu, C. Jung-Hao, C. Kai-Ming, L. Hong-Lin, H. Sheng-Yi, L. Hao-Wu, Perovskite photovoltaics for dim-light applications, Adv. Funct. Mater. 25 (2015) 7064-7070.

[42] M. Law, L.E. Greene, J.C. Johnson, R. Saykally, P. Yang, Nanowire dye-sensitized solar cells, Nat. Mater. 4 (2005) 455.

[43] S. Dharani, H.K. Mulmudi, N. Yantara, P.T. Thu Trang, N.G. Park, M. Graetzel, S. Mhaisalkar, N. Mathews, P.P. Boix, High efficiency electrospun TiO2 nanofiber 
based hybrid organic-inorganic perovskite solar cell, Nanoscale 6 (2014) 1675-1679.

[44] G.Me van de Krol R, Photoelectrochemical Hydrogen Production, Springer, Boston, MA, 2012 (Electronic Materials: Science \& Technology).

[45] A.J. Nozik, Photoelectrochemistry: Applications to solar energy conversion, Annu. Rev. Phys. Chem. 29 (1978) 189-222.

[46] Y.Y. Gurevich, Y.V. Pleskov, Chapter 4 Photoelectrochemistry of semiconductors, in: R.K. Willardson, A.C. Beer (Eds.), Semiconductors and Semimetals, Elsevier, 1983, pp. 255-328 https://www.sciencedirect.com/science/article/pii/ S008087840860277X.

[47] K. Yoshikawa, H. Kawasaki, W. Yoshida, T. Irie, K. Konishi, K. Nakano, T. Uto, D. Adachi, M. Kanematsu, H. Uzu, K. Yamamoto, Silicon heterojunction solar cell with interdigitated back contacts for a photoconversion efficiency over $26 \%$, nature, Energy 2 (2017) 17032. 